\title{
The most effective strategy for recruiting a pregnancy cohort: a tale of two cities
}

\author{
Donna P Manca ${ }^{1 *}$, Maeve O'Beirne ${ }^{2}$, Teresa Lightbody ${ }^{1}$, David W Johnston², Dayna-Lynn Dymianiw², \\ Katarzyna Nastalska ${ }^{1}$, Lubna Anis², Sarah Loehr ${ }^{1}$, Anne Gilbert ${ }^{1}$, Bonnie J Kaplan² and the APrON study team
}

\begin{abstract}
Background: Pregnant women were recruited into the Alberta Pregnancy Outcomes and Nutrition (APrON) study in two cities in Alberta, Calgary and Edmonton. In Calgary, a larger proportion of women obtain obstetrical care from family physicians than from obstetricians; otherwise the cities have similar characteristics. Despite similarities of the cities, the recruitment success was very different. The purpose of this paper is to describe recruitment strategies, determine which were most successful and discuss reasons for the different success rates between the two cities.

Methods: Recruitment methods in both cities involved approaching pregnant women ( $<27$ weeks gestation) through the waiting rooms of physician offices, distributing posters and pamphlets, word of mouth, media, and the Internet.

Results: Between May 2009 and November 2010, 1,200 participants were recruited, 86\% (1,028/1,200) from Calgary and 14\% $(172 / 1,200)$ from Edmonton, two cities with similar demographics. The most effective strategy overall involved face-to-face recruitment through clinics in physician and ultrasound offices with access to a large volume of women in early pregnancy. This method was most economical when clinic staff received an honorarium to discuss the study with patients and forward contact information to the research team.

Conclusion: Recruiting a pregnancy cohort face-to-face through physician offices was the most effective method in both cities and a new critically important finding is that employing this method is only feasible in large volume maternity clinics. The proportion of family physicians providing antenatal and post-natal care may impact recruitment success and should be studied further.
\end{abstract}

Keywords: Pregnant women, Research subjects, Cohort studies

\section{Background}

In recent years it has become more challenging to recruit pregnant women to volunteer for research and many strategies have been employed to increase participation. Studies have found that women decline to participate for a variety of reasons, including a growing number of requests to participate [1], time commitments [2,3], language barriers $[2,4]$, the intrusiveness of the study (e.g., provision of biological specimens) [5,6], lack of interest and/or feeling that there is no perceived benefit from participation $[5,7,8]$, and/or practical considerations such as holiday plans [9]. Although participants may be wary of committing to a project that requires a substantial amount

\footnotetext{
* Correspondence: dpmanca@ualberta.ca

'University of Alberta, Edmonton, AB, Canada

Full list of author information is available at the end of the article
}

of time, a review of large epidemiologic prospective pregnancy studies recruiting women prior to conception found that in some circumstances women are willing to be involved in time-consuming and/or invasive projects over an extended period of time [10].

Researchers have used a variety of methods to enlist pregnant women for studies. Approaching pregnant women directly in prenatal clinics or ultrasound clinics has resulted in response rates between $30 \%$ to $85 \%$ $[5-7,11,12]$. Many randomized clinical trials use media techniques, direct patient contacts, and contact with health care providers, with mixed success [13]. Media techniques that include an article describing the study published in a local newspaper have been effective for some [13]. Newspaper advertisements that do not have detailed study information or are run for a single day in

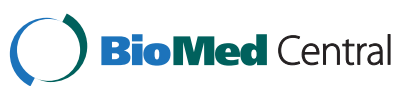

(c) 2013 Manca et al.; licensee BioMed Central Ltd. This is an Open Access article distributed under the terms of the Creative Commons Attribution License (http://creativecommons.org/licenses/by/2.0), which permits unrestricted use, distribution, and reproduction in any medium, provided the original work is properly cited. 
a daily newspaper are less successful [13,14]. Pregnant women have also been successfully recruited via distribution of flyers and posters in locations they frequent such as hospitals $[8,14]$, ultrasound clinics $[8,14]$, laboratories $[8,14]$, pre-natal classes [8], libraries [14], community centers [14], stores [14], coffee shops [14], trade shows and naturopathic and physiotherapy clinics [14].

The Alberta Pregnancy Outcomes and Nutrition project $(\mathrm{APrON})$ is a longitudinal cohort study designed to examine the relationship between nutrient status during pregnancy, maternal mental health, and infant neurodevelopment and mental health. Participants were requested to attend assessments with the researchers once each trimester of their pregnancy and twice after delivery. The time commitment for each visit was approximately one to one and a half hours. They would continue to participate via mail out questionnaires on five occasions until their child was three years of age. The total time commitment was approximately $15-20$ hours per participant over a three and a half year period. Details requirements from the study participants have been published elsewhere [15].

Health care in Canada is provided through a publically funded system. Medical services are governed by the Canada Health Act but are delivered provincially. The Canadian population does not pay for individual visits for medically necessary treatments. Maternity care is fully covered under the system. APrON recruited pregnant women in two cities, Calgary and Edmonton (Alberta). The cities were similar other than the arrangement of maternity care services. In Calgary, there are more high volume family physician-led clinics that provide maternity care. This is reflected in the proportion of births attended by a family physician. In Calgary in $2008,37 \%$ of births were attended by a family physician while obstetricians attended $60 \%$ while in Edmonton, only $18 \%$ of births were attended by family physicians, while obstetricians attended 79\% (Alberta Perinatal Health Program, 2010). Since women with obstetrician assisted births tend to receive their early prenatal care from family physicians, women in Edmonton were spread among many low volume family physicians' offices as compared to the high volume family physicianled clinics in Calgary. This paper describes recruitment strategies used by APrON in these two cities, determines which were most successful and discusses reasons for the different success rates between the two cities.

\section{Methods}

Ethics approval was obtained in 2009 from the Research Ethics Boards at the University of Alberta (HREB biomedical panel Pro00002954) and the University of Calgary (Conjoint Health Research Ethics Board ID E22101).
Participants provided explicit consent prior to participation in the study.

Pregnant women were eligible to participate in APrON if they had a gestational age of less than 27 weeks on entry to the study. Gestation was determined through the women's self-report of gestation and expected date of confinement and included consent for the researchers to access this information on the prenatal and deliver records. Women were ineligible if they were not fluent in English, or were planning to move out of the region in the next 6 months [15]. Numerous strategies were utilized to recruit the pregnancy cohort: some were employed in both cities, and others were unique to Edmonton.

\section{Recruitment strategies common to both cities Physician Offices (family physicians, obstetricians and radiologists)}

Family physician groups providing maternity care saw women early in their pregnancy and accepted referrals from physicians and self-referrals including repeat pregnancies. In Edmonton, in 2007, there were two main family physician groups providing prenatal care and attending women during labor and delivery. One group was estimated to attend 150 births each years and the other, 300 births each year. In Calgary, at the same time, there were three dedicated maternity clinics located at one location estimated to attend 2100 births each year.

A number of strategies involved face-to-face recruitment through physician offices. One method that was used in high volume maternity clinics (family medicine, obstetrical and radiology ultrasound) involved a receptionist directing pregnant women to a research assistant who was available in the waiting room to discuss the study. The research staff offered each pregnant woman a brochure briefly summarizing the project. In another method, clinic staff received a small honorarium or gift of appreciation to discuss the study with patients and forward contact information to the research team. This method was initially used in lower volume clinics but soon became the model of choice for both the low and high volume clinics due to economic feasibility.

\section{Advertising}

Posters and flyers were placed in public spaces that pregnant women were likely to frequent such as physicians' clinics, hospital dietitians, laboratories, birth control centers, pharmacies, urgent care centres, ultrasound centres, grocery stores, maternity and baby stores, public libraries, zoos, botanical gardens, bookstores, yoga and fitness centers and toy stores. 


\section{Word of mouth}

There was much effort expended in both cities to foster interest in the study via word of mouth from doctors, researchers and their staff, and friends and family of participants.

\begin{abstract}
Media
APrON used earned-media (publicity gained through promotional efforts as opposed to paid media). We targeted media outlets with the greatest readership and audiences, as well as those related to pregnancy and nutrition. The study was highlighted on four television news stations (CBC, Global, CTV, and Shaw TV). Additionally, later in the recruitment period, an APrON advertisement ran for 24 hours on a smaller network (Access Network). Radio media was also used to promote the project (CBC French and English, CKUA, 660 News, and QR77). Print media included publications, press releases and stories in major newspapers, smaller papers, and magazines. Detailed information on the mass media including links to news articles are available on the APrON website at http://www.apronstudy.ca/Research/MassMedia.aspx\#.
\end{abstract}

\section{Internet}

Recruitment solicitations were sent through various list servers such as emails through the Provincial Health Authority's Primary Care Networks. Online recruitment involved the APrON website (http://www.apronstudy.ca/), and other postings such as University websites, social media included pages on Facebook (https://www.facebook. com/APrONstudy) and Twitter (https://twitter.com/ apron_research), newspaper on-line articles and Mommy blogs. Participants were not recruited directly from Facebook or Twitter to avoid issues with exposing participants' confidential information. The social medial pages posted information on $\mathrm{APrON}$, including where and how to participate in the study.

\section{Other}

Recruiters were present at early pregnancy and nutrition classes 4 times a month (Calgary) and investigators presented at medical rounds in both cities. Study staff also contacted the Doula Association, Association for Safe Alternatives in Childbirth, midwives and naturopath clinics, centers for pregnant teens, programs to support low income pregnant women, community perinatal programs and the provincial after hours medical help line.

Community supporters such as child/maternity type stores and other businesses (see http://www.apronstudy. ca/GetInvolved/CurrentCommunitySupporters.aspx) who agreed to provide small gifts to participants were asked to spread the word and put the APrON link on their websites. These supporters also provided APrON with gifts that were used for a monthly APrON draw in exchange for free advertising with the supporters' coupons and brochures. Recruiters also attended events such as baby day events in major shopping retailers and malls, craft shows, and a variety of baby fairs, pregnancy trade shows, Welcome Wagon baby showers, and other celebrations and festivals.

\section{Recruitment unique to Edmonton}

There were some important differences between the two cities in strategies used. In Edmonton, APrON initially recruited primarily through the Women and Children's Health Research Institute (WCHRI), which had established a network to recruit pregnant women to all academic pregnancy studies conducted in that city. In addition to APrON, WCHRI was simultaneously recruiting for three other studies.

The WCHRI mode of recruitment involved asking obstetricians and family physicians caring for a high volume of pregnant women to invite their patients to learn more about the study by permitting their contact information to be faxed to the WCHRI central office. WCHRI then took responsibility for forwarding patients' contact information to the appropriate study. If a woman was eligible for more than one study, she was randomly assigned to one of the active studies. Upon receiving the potential participant's contact information, APrON would contact the woman to describe the study, review eligibility criteria, and arrange the first on-site visit. Each group practice with a minimum of 3 physicians was remunerated at $\$ 250 /$ month by WCHRI.

\section{Considerations other than recruitment strategies}

Other factors also affected recruitment. The APrON research sites were initially located in NorthWest Calgary at the Alberta Children's Hospital and in Edmonton on the University Campus. The populations in these areas are of a higher socioeconomic status (SES) and more highly educated than some other areas of the cities. Participants were required to attend these centres to complete surveys and other measures. In order to increase the ethnic diversity of the sample, multiple satellite clinics were later opened in areas of Calgary with a more diverse population, and closer to public transit.

\section{Results}

Recruitment activities such as advertising were initiated in January 2009 and APrON participant recruitment began in May 2009. Of the first 1,200 women recruited, 1,028 (86\%) were in Calgary while only 172 (14\%) were in Edmonton. In 2008 there were 50,164 live births in Alberta with 18,633 live births occurring in Calgary and 14,866 in Edmonton respectively [16]. Thus based upon the proportion of live births alone, we could expect to 
recruit 56\% $(18,633 / 33,399)$ of our sample from Calgary and $44 \%(14,866 / 33,399)$ from Edmonton.

In the first year of the study, many of the women were not asked how and where they heard about the APrON project. Of those who were subsequently asked, Table 1 illustrates the number of participants recruited in Edmonton and Calgary through all recruitment strategies as reported by the women.

\section{Edmonton}

The WCHRI-based recruitment that included multiple studies was notably unsuccessful for APrON. APrON only received 107 referrals from WCHRI and of those, only 19 (18\%) joined the Edmonton APrON cohort. A decision was made to cease recruitment through the WCHRI strategy in September 2010 and active recruitment continued outside the WCHRI mode until November 2010 when a sample of 1,200 was complete.

During the first two weeks at the family practice clinic selected for trialing on-site recruitment in Edmonton, the APrON research assistant spoke to 44 pregnant women. Of these, 15 (34\%) were over 27 weeks gestation; seven declined for other reasons including being too busy $(\mathrm{N}=1)$, being uncomfortable with the blood samples $(\mathrm{N}=2)$, or no reason indicated $(\mathrm{N}=4)$; five took the information but did not want a follow-up call or email; one was already involved with APrON; 13 (30\%) provided their contact information (email and/or phone number) for follow up and three (7\%) booked appointments directly for the research project. After the first two weeks, the majority of women coming to the clinic had already spoken to the researchers.

Additional strategies employed in Edmonton are described in Table 1. Of the 159 Edmonton women who reported on recruitment strategies, the most successful strategies were face-to-face conversations in physician and ultrasound offices (39), word of mouth (37), TV media coverage (20) and advertising through posters and pamphlets (19). Of note, a higher proportion of Edmonton women were recruited by word of mouth than in Calgary. We think this difference was likely due to the inability to obtain adequate access to pregnant women in the clinical setting; hence word of mouth played a larger role in recruitment in Edmonton.

\section{Calgary}

As is clear from Table 1, face-to-face recruitment was also the most effective strategy in Calgary: of 821 Calgary participants, 276 women were obtained from recruiters in doctors' offices, and 180 from recruiters in ultrasound offices.

These results were consistent with those observed in the subsample of 196 women who participated via the satellite clinics established for the purpose of diversifying the Calgary sample. In that subgroup, the most successful strategy was to fully educate the family doctors, who then presented the study to those patients who were potentially interested. As most of the women with diverse cultural backgrounds and/or low SES sought care mostly, if not exclusively, through their family doctor, this approach allowed us the opportunity to access these women the best. The final result was that $62 \%(122 / 196)$ of these women were recruited after their family doctor first introduced the study and asked if they would be willing to hear more from a research assistant, 14\% (27/ 196) were first approached by a research assistant, and $24 \%(47 / 196)$ were recruited by a handful of the other recruitment strategies.

Table 1 Recruitment strategies as reported by the women in Edmonton and Calgary

\begin{tabular}{lll}
\hline City & Edmonton & \multicolumn{1}{c}{ Calgary } \\
\hline Strategy & Number (\%) & Number (\%) \\
\hline Recruitment in medical offices by physicians and office staff & $172 / 1200(14)$ & $1028 / 1200(86)$ \\
\hline Recruitment at medical/ultrasound clinics by APrON staff & $35(22.0)$ & $276(33.6)$ \\
\hline Poster/Pamphlet in medical offices, ultrasound clinics, play group etc. & $4(2.5)$ & $180(21.9)$ \\
\hline Word of mouth from participants; family or friends who are not participants, or from a university employee & $37(23.3)$ & $19(12.0)$ \\
\hline Media - newspaper, magazine & $12(7.5)$ & $7(0.9)$ \\
\hline Media - TV, radio & $20(12.6)$ & $19(2.3)$ \\
\hline Internet - list servers (Health Notes) and others & $20(12.6)$ \\
\hline Internet - APrON website & $9(5.7)$ & $1(0.1)$ \\
\hline Other & $3(1.9)$ & $12(1.5)$ \\
\hline Total & $159(100)$ & $170(20.7)^{*}$ \\
\hline Wom
\end{tabular}

Women reported on the one method they identified as responsible for recruiting them into the APrON project.

*Other for Calgary includes the following: Pregnancy/Nutrition Class: 23 (2.8); Baby Fairs: 13 (1.6).

Media Public Service Announcement (unpaid media): 5 (0.6); Other: 115 (14.0). 


\section{Comparison of sociodemographic variables}

Maternal age, income, education, employment status and ethnicity were similar in both cities (Table 2) and though Calgary had a slightly higher SES there were no significant differences in the data using non-parametric statistical analysis (Fisher's exact test and Chi-square). However, Calgary was able to recruit a small number of participants without high school education whereas all of Edmonton's participants had high school education or higher.

\section{Discussion}

The most effective strategy overall was face-to-face recruiting through physicians' offices, including ultrasound offices. The cost of face-to-face recruiting is highly influenced by the structure of the health care delivery model. In Edmonton, early pregnancy care is distributed throughout the city in family physician offices and later care in obstetrician offices, whereas in Calgary about half of the early pregnancy care occurs in high volume family medicine obstetrical clinics. This difference likely affected APrON's recruitment success. The distribution of pregnant women in many clinics in Edmonton was a challenge as we could not afford the cost of establishing so many recruitment sites: there are more than 1000 Edmonton family physicians registered with the Alberta College of Physicians and Surgeons. Others have described access to eligible women as a limitation of recruiting pregnant women directly in clinical settings $[6,11,14]$. Also, having more prenatal care provided by obstetricians meant that it was more difficult to recruit women $<27$ weeks gestation. Although placing recruiters in physician offices was more cost effective in the high volume family medicine maternity clinics in Calgary, it was still more efficient to pay an honorarium to the respective practice nurses. Hence a city that has a higher proportion of family physicians providing antenatal care and attending women during labor and delivery may enhance the success of researchers attempting to access pregnant women. Recruiting from waiting rooms may have been more effective if there had been no restriction on gestational age.

In Edmonton, with the lack of access to high volume early maternity clinics, the media appeared to be particularly successful in gaining interest in the APrON study. It is important to note that these were actual media stories about the research project rather than paid advertisements seeking recruits. Other research has confirmed that media coverage is more successful than media advertisements in recruiting women to studies [13]. Posters and pamphlets in medical offices were also productive, which is consistent with the report of other research where flyers/posters garnered the greatest interest in their pregnancy related study [14]

Although not calculated precisely, research assistants reported that many women recruited in physicians' offices had already heard about APrON. Media coverage and other advertisement exposure may prime potential participants to be receptive to enrolling in a research project, so that even though their recruitment is attributed to direct approach in physicians' offices, the media heightening awareness of the study was likely influential.

There were, however other variations in recruitment methods that may have contributed to the differences in success between the two cities. In Edmonton a collaborative method was used through WCHRI, which may not have been as successful in providing access to eligible women because APrON was competing with other projects and the women did not have a choice as to which project they were assigned. Recruitment through WCHRI primarily involved obstetricians which also may account for the poor success in accessing women who were $<27$ weeks gestation.

Another difference between Edmonton and Calgary was the variation in the scheduling of women attending radiology clinics for first and second trimester fetal screening. In Calgary, researchers were able to access numerous pregnant women who attended the ultrasound clinic via block scheduling while in Edmonton pregnant women were mixed in with other patients being seen for health concerns, limiting the number of pregnant women in the clinic at any one time.

On average, the participants from both cities were of relatively high SES. In Calgary, the high SES of the participants may have been influenced by the location of the primary APrON research site. This unit is difficult to access by transit and thus participants needed a car. On the other hand, other researchers have found that pregnant women of higher SES are generally more likely to participate in pregnancy-related research studies, so perhaps the skewed SES would have occurred no matter where the research sites were located $[8,14]$. APrON participants were also more highly educated than the general population with almost all of them having obtained at least high school education, that is, only 9.7\% had only high school or less than a high school education. In the total Alberta population of women aged 25 to 34 in $2005,12 \%(27,845 / 234,175)$ did not have a high school education (no certificate, diploma or degree) [17]. The higher educational level of volunteers is consistent with the findings of other studies. In one cohort study of 152 pregnant women [14], women were somewhat older, predominantly Caucasian, more affluent, and better educated than the general population of pregnant and non-pregnant women residing in Vancouver [14], and in an Italian internet-based mother- 
Table 2 Description of Calgary and Edmonton APrON Participants ${ }^{1}$

\begin{tabular}{|c|c|c|c|c|c|c|c|c|}
\hline \multicolumn{3}{|c|}{ Calgary } & \multicolumn{3}{|c|}{ Edmonton } & \multicolumn{3}{|c|}{ Total } \\
\hline & $\mathbf{N}$ & $\begin{array}{l}\text { Percentage } \\
\text { within site }\end{array}$ & $\begin{array}{l}\text { Percentage } \\
\text { of total }\end{array}$ & $\mathrm{N}$ & $\begin{array}{l}\text { Percentage } \\
\text { within site }\end{array}$ & $\begin{array}{l}\text { Percentage } \\
\text { of total }\end{array}$ & $\mathbf{N}$ & $\begin{array}{c}\text { Percentage } \\
\text { of total }\end{array}$ \\
\hline \multicolumn{9}{|l|}{ Income } \\
\hline$<\$ 20,000$ & 21 & $2.1 \%$ & $1.8 \%$ & 0 & $0.0 \%$ & $0.0 \%$ & 21 & $1.8 \%$ \\
\hline$\$ 20,000-\$ 39,000$ & 38 & $3.9 \%$ & $3.3 \%$ & 9 & $5.4 \%$ & $0.8 \%$ & 47 & $4.1 \%$ \\
\hline$\$ 40,000-\$ 69,000$ & 130 & $13.3 \%$ & $11.3 \%$ & 18 & $10.7 \%$ & $1.6 \%$ & 148 & $12.9 \%$ \\
\hline$\$ 70,000-\$ 99,00$ & 209 & $21.3 \%$ & $18.2 \%$ & 49 & $29.2 \%$ & $4.3 \%$ & 258 & $22.5 \%$ \\
\hline$\$ 100,000+$ & 581 & $59.3 \%$ & $50.7 \%$ & 92 & $54.8 \%$ & $8.0 \%$ & 673 & $58.7 \%$ \\
\hline Total & 979 (missing 49) & & & 168 (missing 4) & & & 1147 (missing 53) & \\
\hline \multicolumn{9}{|l|}{ Education } \\
\hline Trade/ & 893 & $90.2 \%$ & $77.0 \%$ & 154 & $91.1 \%$ & $13.3 \%$ & 1047 & $90.3 \%$ \\
\hline \multicolumn{9}{|l|}{ Under-graduate/ } \\
\hline \multicolumn{9}{|l|}{ Post Graduate } \\
\hline High School/< & 97 & $9.8 \%$ & $8.4 \%$ & 15 & $8.9 \%$ & $1.3 \%$ & 112 & $9.7 \%$ \\
\hline \multicolumn{9}{|l|}{ High School } \\
\hline Total & 990 (missing 38) & & & 169 (missing 3) & & & 1159 (missing 41) & \\
\hline \multicolumn{9}{|c|}{ Working at a paid job } \\
\hline Yes & 732 & $72.6 \%$ & $62.1 \%$ & 131 & $76.6 \%$ & $11.1 \%$ & 863 & $73.2 \%$ \\
\hline No & 276 & $27.4 \%$ & $23.4 \%$ & 40 & $23.4 \%$ & $3.4 \%$ & 316 & $26.8 \%$ \\
\hline Total & 1008 (missing 20) & & & 171 (missing 1) & & & 1179 (missing 21) & \\
\hline \multicolumn{9}{|l|}{ Marital status } \\
\hline Married/ & 950 & $96.3 \%$ & $82.0 \%$ & 165 & $96.5 \%$ & $14.2 \%$ & 1115 & $96.3 \%$ \\
\hline \multicolumn{9}{|l|}{ Common-Law } \\
\hline Single/ & 37 & $3.7 \%$ & $3.2 \%$ & 6 & $3.5 \%$ & $0.5 \%$ & 43 & $3.7 \%$ \\
\hline \multicolumn{9}{|l|}{ Divorced/ } \\
\hline \multicolumn{9}{|l|}{ Separated } \\
\hline Total & 987 (missing 41) & & & 171 (missing 1) & & & 1158 (missing 42) & \\
\hline \multicolumn{9}{|l|}{ Ethnicity } \\
\hline Caucasian & 841 & $86.3 \%$ & $73.6 \%$ & 146 & $86.9 \%$ & $12.8 \%$ & 987 & $86.4 \%$ \\
\hline Non-Caucasian & 134 & $13.7 \%$ & $11.7 \%$ & 22 & $13.1 \%$ & $1.9 \%$ & 156 & $13.6 \%$ \\
\hline Total & 975 (missing 53) & & & 168 (missing 4) & & & 1143 (missing 57) & \\
\hline
\end{tabular}

'Denominators vary due to missing data.

child cohort study, participants were older, had higher educational levels, and were more often primiparous [8]. Although in general the two Alberta cities are quite similar, Calgary's population appears to have a slightly higher SES than Edmonton's with a higher overall median family income (77,658 versus 69,214), fewer individuals $\geq 15$ years of age without certificates or diplomas $18 \%(145,125 / 801,265)$ versus $22 \%(131,220 / 598.905)$, and a lower unemployment rate of 4.1 versus 4.9 [17,18]. While Edmonton's population is slightly smaller and consists of a slightly lower SES [17] it seems unlikely that this difference alone would explain the large disparity in recruitment success between the two cities. It is more likely that the greater success in Calgary was attributable to the availability of family physician-led high volume maternity clinics.

\section{Conclusion}

In summary, we had the unusual opportunity of being able to compare recruitment strategies and success in two very similar cities in a single study. It is an interesting finding that in both cities the most successful method was through face-to-face strategies in physician offices, a method that is feasible only in settings that have access to large volume maternity clinics with women in early pregnancy, a new critically important finding. Hence, we concluded that a major influence on recruitment success was the health care model, which differed between the two cities. Our results suggest that the proportion of family physicians providing antenatal and post-natal care may be a significant factor in determining recruitment success and should be studied further. 


\section{Competing interests}

None of the authors have any personal or financial conflict of interest.

\section{Authors' contributions}

DM - involved in development of the recruitment strategy and follow-up, conceived and designed the paper, involved with conducting the initial literature review, wrote the first draft manuscript. $\mathrm{MO}$ - involved in development of the recruitment strategy and follow-up, conceived and designed the paper, reviewed the initial literature review. TL - involved in development of the recruitment strategy and follow-up, conceived and designed the paper, involved with conducting the initial literature review, wrote the first draft manuscript. DJ - involved in development of the recruitment strategy and follow-up, helped to conceive and design the paper, involved with reviewing the initial literature review, assisted with the drafts. DD - involved in development of the recruitment strategy and followup, contributed to the conception, composition of the article. KN- involved in implementation of the recruitment strategy and follow-up, contributed to the conception, composition of the article. LA - involved in development of the recruitment strategy and follow-up, contributed to the conception, composition of the article. SL - contributed to the conception, composition of the article. AG - contributed to the conception, composition of the article. BK - principal investigator, involved in development of the recruitment strategy and follow-up, conceived and designed the paper, reviewed the initial literature review. All authors were involved in the drafts and revisions and read and approved the final manuscript.

\section{Acknowledgements}

APrON received funding from the Alberta Heritage Foundation for Medical Research, currently Alberta Innovates - Health Solutions (AIHS). We are extremely grateful to all the families who took part in this study and the whole APrON team (www.apronstudy.ca/), investigators, research assistants, graduate and undergraduate students, volunteers, clerical staff and managers, and community businesses. The individual members of the APrON research team are Bonnie J. Kaplan, Catherine J. Field, Deborah Dewey, Rhonda C. Bell, Francois P. Bernier, Marja Cantell, Linda M. Casey, Misha Eliasziw, Anna Farmer, Lisa Gagnon, Gerald F. Giesbrecht, Laki Goonewardene, David W. Johnston, Libbe Kooistra, Nicole Letourneau, Donna P. Manca, Jonathan W. Martin, Linda J. McCargar, Maeve O'Beirne, Victor J. Pop, Nalini Singhal. We are also grateful to the Women and Children's Health Research Institute (WCHRI) for assisting us with recruitment, and the Alberta Children's Hospital Research Institute (ACHRI) for ongoing support.

\section{Author details}

${ }^{1}$ University of Alberta, Edmonton, $\mathrm{AB}$, Canada. ${ }^{2}$ University of Calgary, Calgary, $A B$, Canada.

Received: 4 January 2013 Accepted: 19 March 2013

Published: 22 March 2013

\section{References}

1. Galea S, Tracy M: Participation rates in epidemiologic studies. Ann Epidemiol 2007, 17(9):643-653.

2. Brown BA, Long HL, Milliken N: What's to know about study recruitment? We asked recruiters. Women's health issues: official publication of the Jacobs Institute of Women's Health 2002, 12(3):116-121.

3. Sharp L, Cotton SC, Alexander L, Williams E, Gray NM, Reid JM, Group T: Reasons for participation and non-participation in a randomized controlled trial: postal questionnaire surveys of women eligible for TOMBOLA (Trial Of Management of Borderline and Other Low-Grade Abnormal smears). Clin Trials 2006, 3(5):431-442.

4. Tooher RL, Middleton PF, Crowther CA: A thematic analysis of factors influencing recruitment to maternal and perinatal trials. BMC Pregnancy Childbirth 2008, 8:36.

5. El-Khorazaty MN, Johnson AA, Kiely M, El-Mohandes AA, Subramanian S, Laryea HA, Murray KB, Thornberry JS, Joseph JG: Recruitment and retention of low-income minority women in a behavioral intervention to reduce smoking, depression, and intimate partner violence during pregnancy. BMC Public Health 2007, 7:233.
6. Savitz DA, Dole N, Williams J, Thorp JM, McDonald T, Carter AC, Eucker B Determinants of participation in an epidemiological study of preterm delivery. Paediatr Perinat Epidemiol 1999, 13(1):114-125.

7. Mihrshahi S, Vukasin N, Forbes S, Wainwright C, Krause W, Ampon R, Mellis C, Marks G, Peat J: Are you busy for the next 5 years? Recruitment in the Childhood Asthma Prevention Study (CAPS). Respirology 2002, 7(2):147-151.

8. Richiardi L, Baussano I, Vizzini L, Douwes J, Pearce N, Merletti F, Cohort N: Feasibility of recruiting a birth cohort through the Internet: the experience of the NINFEA cohort. Eur J Epidemiol 2007, 22(12):831-837.

9. Jefferies $K$, Price $C$, Morgan J: To participate or not in research? Birth 2006, 33(1):86

10. Buck GM, Lynch CD, Stanford JB, Sweeney AM, Schieve LA, Rockett JC, Selevan SG, Schrader SM: Prospective pregnancy study designs for assessing reproductive and developmental toxicants. Environmental Health Perspectives 2004, 112(1):79-86

11. Chasan-Taber L, Fortner RT, Hastings V, Markenson G: Strategies for recruiting Hispanic women into a prospective cohort study of modifiable risk factors for gestational diabetes mellitus. BMC Pregnancy Childbirth 2009, 9:57.

12. Kramer MS, Wilkins R, Goulet L, Seguin L, Lydon J, Kahn SR, McNamara H, Dassa C, Dahhou M, Masse A, et al: Investigating socio-economic disparities in preterm birth: evidence for selective study participation and selection bias. Paediatr Perinat Epidemiol 2009, 23(4):301-309.

13. Korde LA, Micheli A, Smith AW, Venzon D, Prindiville SA, Drinkard B, Sebring N, Smith MD, Zujewski JA, Eng-Wong J: Recruitment to a physical activity intervention study in women at increased risk of breast cancer. BMC Med Res Methodol 2009, 9:27.

14. Webster GM, Teschke $K$, Janssen PA: Recruitment of healthy first-trimester pregnant women: lessons from the Chemicals, Health \& Pregnancy study (CHirP). Matern Child Health J 2012, 16(2):430-438.

15. Kaplan BJ, Giesbrecht GF, Leung BM, Field CJ, Dewey D, Bell RC, Manca DP O'Beirne M, Johnston DW, Pop VJ, et al: The Alberta Pregnancy Outcomes and Nutrition (APrON) cohort study: rationale and methods. Matern Child Nutr 2012

16. Reproductive Health Working Group: Alberta Reproductive Health: Pregnancies and Births 2009. Edmonton, AB: Alberta Health and Wellness; 2009.

17. Statistics Canada: (Code4811061) (table) Statistics Canada Catalogue no. 92591-XWE: 2006 Community Profiles. Edmonton, Alberta: 2006 Census; 2007. http://www12.statcan.gc.ca/census-recensement/2006/dp-pd/prof/92-591/ index.cfm?Lang=E

18. Statistics Canada: (Code4806016) (table) Statistics Canada Catalogue no. 92591-XWE: 2006 Community Profiles. Calgary, Alberta: 2006 Census; 2007. http://www12.statcan.ca/census-recensement/2006/dp-pd/prof/92-591/ index.cfm?Lang=E.

doi:10.1186/1471-2393-13-75

Cite this article as: Manca et al: The most effective strategy for recruiting a pregnancy cohort: a tale of two cities. BMC Pregnancy and Childbirth 2013 13:75.

\section{Submit your next manuscript to BioMed Central and take full advantage of:}

- Convenient online submission

- Thorough peer review

- No space constraints or color figure charges

- Immediate publication on acceptance

- Inclusion in PubMed, CAS, Scopus and Google Scholar

- Research which is freely available for redistribution 